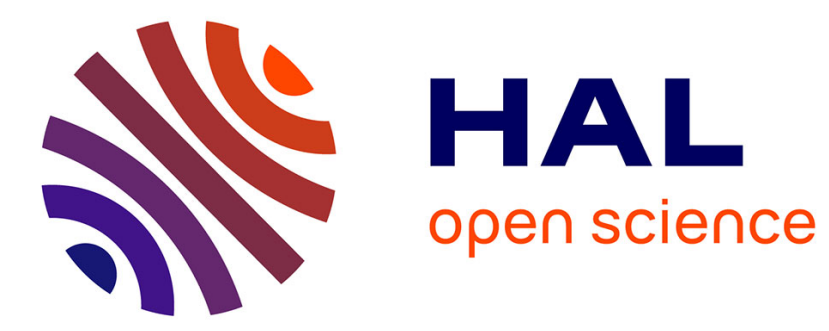

\title{
Effect of gamma irradiation on tensile properties of low molecular weight polyethylene samples
}

Xavier Colin, Carole Monchy-Leroy, Jacques Verdu

\section{To cite this version:}

Xavier Colin, Carole Monchy-Leroy, Jacques Verdu. Effect of gamma irradiation on tensile properties of low molecular weight polyethylene samples. Radiation Physics and Chemistry, 2011, 80 (8), pp.895901. 10.1016/j.radphyschem.2011.04.003 . hal-02428537

\section{HAL Id: hal-02428537 https://hal.science/hal-02428537}

Submitted on 6 Jan 2020

HAL is a multi-disciplinary open access archive for the deposit and dissemination of scientific research documents, whether they are published or not. The documents may come from teaching and research institutions in France or abroad, or from public or private research centers.
L'archive ouverte pluridisciplinaire HAL, est destinée au dépôt et à la diffusion de documents scientifiques de niveau recherche, publiés ou non, émanant des établissements d'enseignement et de recherche français ou étrangers, des laboratoires publics ou privés. 


\title{
Effect of gamma irradiation on tensile properties of low molecular weight polyethylene samples
}

\author{
Xavier Colin ${ }^{\mathrm{a}, *}$, Carole Monchy-Leroy ${ }^{\mathrm{b}}$, Jacques Verdu ${ }^{\mathrm{a}}$ \\ a ARTS ET METIERS ParisTech, PIMM, 151 Boulevard de l'Hôpital, 75013 Paris, France \\ ${ }^{\mathrm{b}}$ EDF RED, Avenue des Renardières, Ecuelles, 77818 Moret-sur-Loing Cedex, France
}

\begin{abstract}
A B S T R A C T
Three high density polyethylene (PE) samples of different origins, with weight average molar masses ranging from 38 to $63 \mathrm{~kg} \mathrm{~mol}^{-1}$ and displaying a semi-ductile behavior with strain at break $\varepsilon_{R}$ values of the order of $100-140 \%$, were gamma irradiated under nitrogen for doses up to $33.3 \mathrm{kGy}$. Steric exclusion chromatography and rheometry allowed to quantify the crosslink density $X$. This later reached values ranging from 4.6 to $9.0 \times 10^{-3} \mathrm{~mol} \mathrm{~kg}^{-1}$, i.e. situated below the gelation point. Differential calorimetry, density measurement and small angle X-rays scattering showed the absence of significant changes in the crystalline morphology, especially lamellar dimensions. Tensile testing revealed an unexpected trend towards brittle regime of fracture while yield stress increases significantly at low doses. It appeared that branching disfavors cavitation during yielding, but this effect is not favorable to ductility.
\end{abstract}

Keywords:

Polyethylene

Ductile-brittle transition

Irradiation

Crosslinking

\section{Introduction}

Polyethylene (PE) samples are ductile or brittle in tension at ambient temperature and strain rates of the order of $10^{-3 \pm 2} \mathrm{~s}^{-1}$, depending on their molar mass distribution and crystalline morphology. Judging ductility from the strain at break in tension $\varepsilon_{R}$ and plotting $\varepsilon_{R}$ against weight average molar mass $M_{W}$, one can well put in evidence the existence of a critical molar mass interval clearly separating a ductile domain from a brittle domain (Fig. 1).

A recent compilation (Fayolle et al., 2008) showed that the transition interval could extend from about 40 to about $100 \mathrm{~kg} \mathrm{~mol}^{-1}$. Considering, in a first approach, that the broadness of the transition is only due to the data scatter and that the existence of a critical molar mass, $M_{F} \approx 70 \pm 30 \mathrm{~kg} \mathrm{~mol}^{-1}$, corresponds to a physical reality, one could remark that $M_{F}$ is about two order of magnitude higher than the entanglement molar mass $M_{e}\left(0.8-3.5 \mathrm{~kg} \mathrm{~mol}^{-1}\right)$ depending on the authors (Wu, 1989; Van Krevelen, 1990; Graessley, 1992; Fetters et al. 1996). It appears clearly that there is no relationship between the onset of ductility and the onset of entanglement in the amorphous phase.

If molar mass does not play a direct role through entanglement density, this means that another (molar mass dependent) structural factor plays a role at another scale. The characteristics that come immediately in mind are lamellar dimensions, of which the role in fracture behavior has raised up an abundant literature

\footnotetext{
* Corresponding author. Tel.: +331442461 47; fax: + 33144246290 .

E-mail address: xavier.colin@ensam.eu (X. Colin).
}

(Trankner et al., 1994; Galeski, 2005; Henning and Michler, 2005; Plummer, 2005). Among lamellar dimensions, the lamella thickness $\ell_{C}$ must be considered (Kennedy et al., 1994; Nitta and Tanaka, 2001), but it sharply depends on thermal treatments so that it could not explain the existence of a well marked transition in the $M_{W}$ scale.

The thickness $\ell_{a}$ of the amorphous layer separating two adjacent lamellas is in contrast a good candidate because it depends only slightly on thermal treatments and increases regularly with molar mass (Kennedy et al., 1994). By comparing linear PE samples differing by their molar masses and thermal treatments, Kennedy et al. (1994) put effectively in evidence the existence of a critical value $\ell_{a c}$ of $\ell_{a}: \ell_{a c} \approx 6-7 \mathrm{~nm}$, so that the tensile behavior is systematically ductile for $\ell_{a}>\ell_{a c}$, and brittle for $\ell_{a}<\ell_{a c}$. A similar result, with about the same $\ell_{a c}$ value, was recently found for polyoxymethylene (Fayolle et al., 2009).

The mechanism of ductile-brittle transition remains still unexplained. Is it just a problem of micromechanics linked to the dependence of local stress state with lamellar dimensions? Or does the tie-macromolecules concentration (TMC) play the key role? There are ways to estimate TMC from lamellar dimensions and molar mass (Krigbaum et al., 1964; Huang and Brown, 1991; Seguela, 2005), but experimental validations are difficult from comparisons of samples differing only by molar mass distribution because all the important parameters, $M_{W}, \ell_{a}$ and TMC, are interrelated and cannot be varied independently. This is the reason why it seemed to us interesting to try a new approach, which can be summarized as follows: samples chosen in such way as they are initially in the ductilebrittle transition region are crosslinked by gamma irradiation 

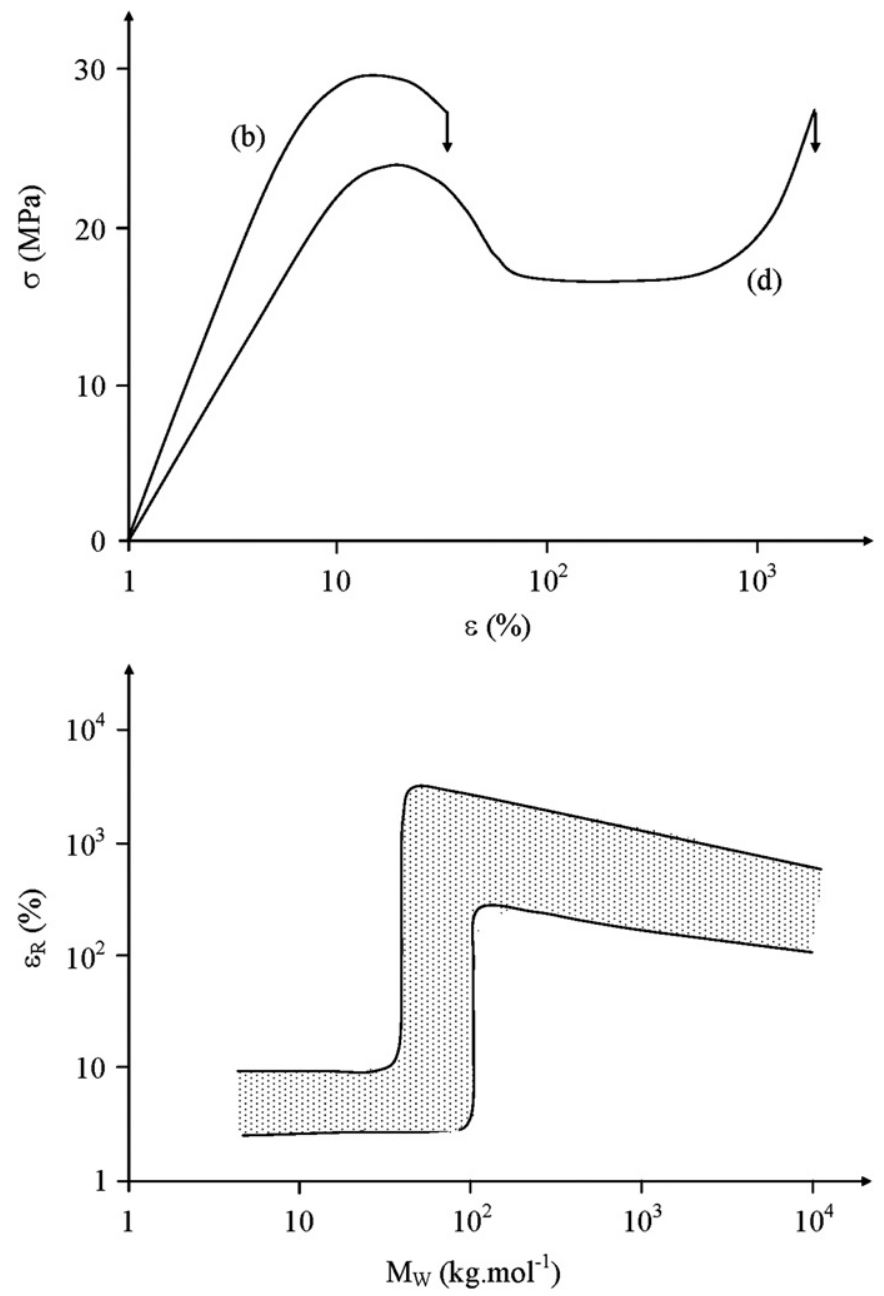

Fig. 1. Top: Shape of tensile curves for ductile (d) and brittle (b) samples in engineering coordinates. Bottom: Shape of the curve strain at break-weight average molar mass for linear PE.

in neutral atmosphere, in order to increase the TMC without changing the lamellar morphology.

Three kinds of crosslinks can be formed: (a) intramolecular crosslinks, (b) intermolecular crosslinks between chain segments belonging to the same lamella and (c) intermolecular crosslinks between chain segments coming from two distinct lamellas. Of course, every crosslink of type (c) generates a new tie macromolecule. Crosslinks of types (a) and (b) are partly inactive from this point of view, but they can be partly active through loop formation or entanglement trapping, as schematized in Fig. 2.

The low gelation dose of $\mathrm{PE}$ indicates that intramolecular crosslinking must be a relative rare event. It appears difficult to appreciate the relative part of crosslinking of type (b) in interlamellar crosslinking, but what is sure is that a non-negligible part of crosslinking events must contribute to the creation of new tie macromolecules.

The effect (or absence of effect) of irradiation on tensile ultimate properties must give, in principle, interesting information on the eventual role of TMC in ductile-brittle transition.

\section{Experimental}

Three high density PEs, referenced as A, B and C, with a high melt flow index (typically MFI $>30 \mathrm{~g} / 10$ min under $2.16 \mathrm{~kg}$ at
$190{ }^{\circ} \mathrm{C}$ ), were selected for the present study. They were supplied as pellets by three distinct companies (Table 1 ).

Dumbbell specimens of $20 \mathrm{~mm}$ length and cross sectional area of $4 \mathrm{~mm}$ width and $2 \mathrm{~mm}$ thickness were molded by a DK CODIM 175-400 injection machine in a cold mold regulated at $40{ }^{\circ} \mathrm{C}$ using the following processing conditions: $\mathrm{T}$ molten polymer $=$

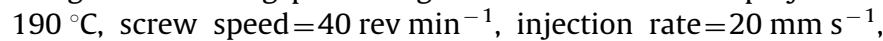
commutation pressure $=170 \mathrm{bar}$, hold pressure $=140 \mathrm{bar}$, hold time $=6 \mathrm{~s}$ and cooling time $=25 \mathrm{~s}$.

Irradiations were performed using a ${ }^{60} \mathrm{Co} \gamma$-rays source at ambient temperature under nitrogen (IONISOS facilities, Dagneux, France) at $2 \mathrm{kGy} \mathrm{h}^{-1}$ dose rate for doses up to $33.3 \mathrm{kGy}$.

Before and after irradiation, samples were characterized by different common analytical techniques. Weight average molar masses $M_{W}$ were determined by steric exclusion chromatography (SEC) in 1,2,4-trichlorobenzene at $145^{\circ} \mathrm{C}$ on a Waters $150 \mathrm{C}$ ALC/GPC apparatus. This one was equipped by three styragel columns giving access to three distinct exclusion windows, $\left[4 \times 10^{6}-5 \times 10^{4}\right],\left[6 \times 10^{5}-5 \times 10^{3}\right]$ and $\left[3 \times 10^{4}-5 \times 10^{2}\right]$, and a refractometer detector. It was previously calibrated using 17 polystyrene (PS) samples.

Complex melt viscosity $\eta^{*}$ was measured at $160{ }^{\circ} \mathrm{C}$ under nitrogen with a Rheometrics ARES rheometer using a coaxial parallel plate geometry ( $25 \mathrm{~mm}$ diameter and $1 \mathrm{~mm}$ gap). Sweep angular frequency experiments $\left(\omega=10^{-2}-10^{2} \mathrm{rad} \mathrm{s}^{-1}\right)$ were performed with a strain amplitude of $5 \%$.

Melting temperature $T_{m}$ and enthalpy of fusion $\Delta H_{m}$ were determined by differential calorimetry (DSC) with a TA Instruments Q10 apparatus driven by a Q Series Explorer Software. Appropximately $10 \mathrm{mg}$ of sample was introduced in a close aluminum pan and subjected to a $10{ }^{\circ} \mathrm{C} \mathrm{min}^{-1}$ ramp from 50 to $200{ }^{\circ} \mathrm{C}$ under nitrogen with a $50 \mathrm{ml} \mathrm{min}^{-1}$ flow rate. Crystallinity ratio was deduced using the classical relationship:

$\chi_{C}=\frac{\Delta H_{m}}{\Delta H_{m 0}} \times 100$

where $\Delta H_{m 0}$ is the enthalpy of fusion of the crystalline phase $\left(\Delta H_{m 0}=292 \mathrm{~kJ} \mathrm{~mol}^{-1}\right)$.

Long period spacing $\ell_{P}$ was determined by Small Angles X-rays scattering (SAXS). The X-rays source is a low power delivery system GENIX ${ }^{\circledR}$ from XENOCS $^{\circledR}$, which provides a high flux collimated beam with a low divergence. The selected tension and intensity were $30 \mathrm{kV}$ and $40 \mathrm{~mA}$, respectively. The wavelength used was the $K_{\alpha 1}$ copper radiation $\left(\lambda_{K \alpha 1}=1.54 \AA\right)$. The SAXS patterns were recorded by means of a MAR340 ${ }^{\circledR}$ image plate detector from Marresearch, with a resolution of $150 \mu \mathrm{m}$ per pixel and located at $1.2 \mathrm{~m}$ from the sample. The SAXS patterns were analyzed, thanks to Fit2D ${ }^{\circledR}$ software, and modified by the Lorentz correction. The long period was then calculated as:

$\ell_{P}=\frac{2 \pi}{q_{\max }} \quad$ (in nm)

where $q_{\max }$ corresponds to the value of the scattering vector $q$ for the maximum of the product of the scattered intensity $I$ by the scattering vector at power two $q^{2}$ (i.e. the maximum of $I \times q^{2}$ ).

Tensile properties were determined on an INSTRON 4301 machine at $23{ }^{\circ} \mathrm{C}, 50 \% \mathrm{RH}$, with a $7.5 \times 10^{-3} \mathrm{~s}^{-1}$ strain rate.

\section{Results}

\subsection{SEC measurements}

Weight average molar masses $M_{W}$, determined by SEC, are listed in Table 2. They increase upon irradiation for all the samples, showing a clear predominance of crosslinking over chain 
a

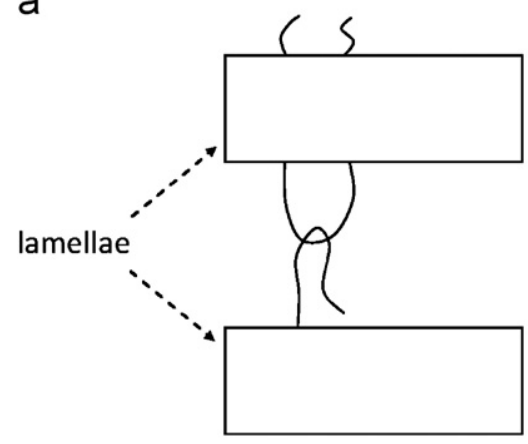

b

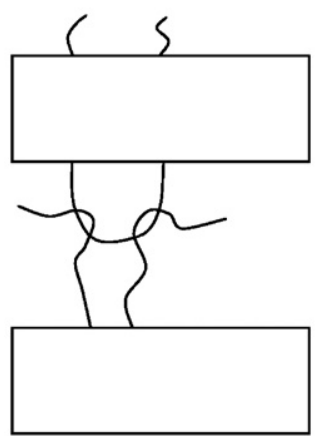

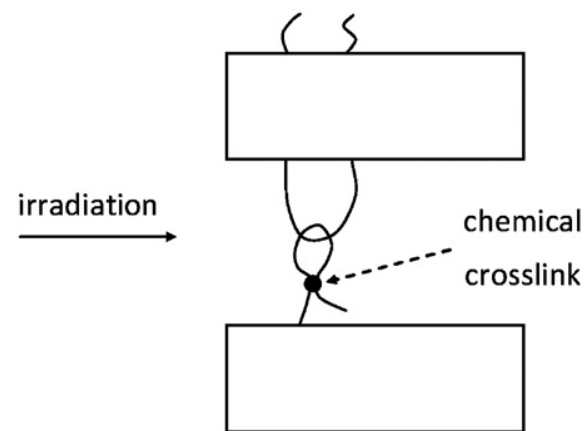

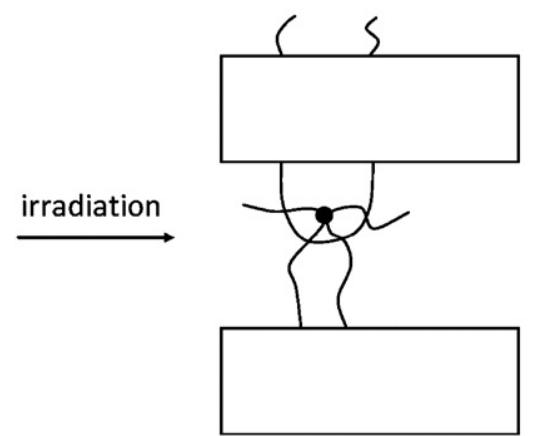

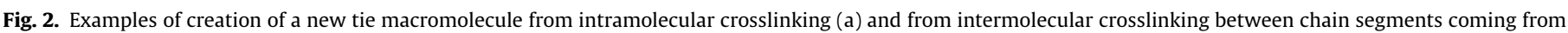
the same lamella (b).

Table 1

Code and suppliers of as received high density PE pellets.

\begin{tabular}{llll}
\hline Reference & A & B & C \\
\hline Supplier & Exxon Mobil & Polimeri Europa & Daelim \\
Density & 0.954 & 0.955 & 0.961 \\
\hline
\end{tabular}

scission. Neglecting this later, in a first approach, we have calculated the number of crosslinking events $X$ per mass unit (Saito, 1958):

$X=\frac{1}{2}\left(\frac{1}{M_{W 0}}-\frac{1}{M_{W}}\right)$

The values of $X$ are listed in Table 2 .

The radiochemical yield for crosslinking $G(X)$ was then determined using the following relationship:

$G(X)=10^{7} \frac{X}{d}$

where $X$ is in $\mathrm{mol} \mathrm{kg} \mathrm{kg}^{-1}, d$ in Gy and $G(X)$ in number of crosslinking events per $100 \mathrm{eV}$ absorbed.

$G(X)$ values are listed in Table 2 . For samples of higher molar mass, most frequently reported $G(X)$ values are of the order of 2 (Chapiro, 1962; Parkinson et al., 1965; Schnabel, 1978). They are close to these values for samples $\mathrm{B}$ and $\mathrm{C}$, but significantly higher for $A$.

\subsection{Rheometric measurements}

The real part $\eta$ of the complex viscosity was recorded against angular frequency $\omega$. An example of the curves $\eta=f(\omega)$ is shown in Fig. 3 for sample A. All the other samples behave in the same way. The viscosity increases in the whole frequency domain and the Newtonian plateau tends to disappear, as expected for a branching process.

The melt viscosity values at an arbitrarily chosen low frequency, $0.1 \mathrm{rad} \mathrm{s}^{-1}$, are listed in Table 2. For non-irradiated samples, which display a Newtonian behavior, the values of the ratio $\eta_{0} / M_{W 0}^{3.4}$ are given in Table 3 .

Except for sample B, $K$ values are remarkably close, showing that the well known power law:

$\eta_{0}=K M_{W 0}^{3.4}$

can be used to predict the melt viscosity. Here, one can take $\left.K=1.44 \times 10^{-3} \mathrm{~Pa} \mathrm{~s}(\mathrm{~mol} \mathrm{~kg})^{-1}\right)^{3.4}$, which corresponds to about $9.1 \times 10^{-14} \mathrm{~Pa} \mathrm{~s}\left(\mathrm{~mol} \mathrm{~g}^{-1}\right)^{3.4}$ (at $160{ }^{\circ} \mathrm{C}$ ) against $5.0 \times 10^{-14} \mathrm{~Pa} \mathrm{~s}$ $\left(\mathrm{mol} \mathrm{g}^{-1}\right)^{3.4}$ literature value (Saeda et al., 1971). There are many possible sources of systematic error in SEC or in rheometric measurements, explaining such a discrepancy. Applied to sample $\mathrm{B}$, the power law, with the chosen $K$ value, would lead to a systematic underestimation of about $15 \%$, which is acceptable in the first approach.

However, the power law is no longer valid for branched samples. It seemed to us interesting to try to find an empirical relationship for the influence of branching. The ratio $\eta / \eta_{0}$ increases quasi-exponentially with the crosslink density $X$, as shown by the plot, $\operatorname{Ln}\left(\eta / \eta_{0}\right)=f(X)$ (Fig. 4):

$\eta=K M_{W 0}^{3.4} \exp (\alpha X)$

where at $160{ }^{\circ} \mathrm{C}, K=1.44 \times 10^{-3} \mathrm{~Pa} \mathrm{~s}\left(\mathrm{~mol} \mathrm{~kg}^{-1}\right)^{3.4}$ and $\alpha=532$ $\mathrm{kg} \mathrm{mol}^{-1}$.

Theoretical gelation point corresponds to (Saito, 1958; Charlesby and Pinner, 1959; Miller and Macosko, 1976):

$X_{g}=\frac{1}{2 M_{W 0}}$

$X_{\text {g }}$ ranges from about $8 \times 10^{-3} \mathrm{~mol} \mathrm{~kg}^{-1}$ (sample C) to $1.3 \times$ $10^{-3} \mathrm{~mol} \mathrm{~kg}^{-1}$ (sample A). In other words, the samples irradiated at the highest dose (33.3 kGy) are not very far from the gel point 
Table 2

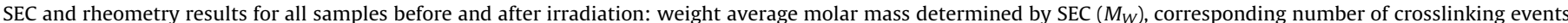

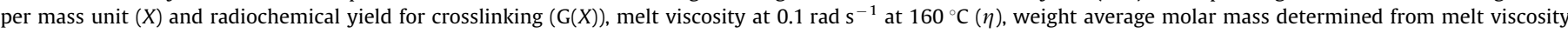
$\left(M^{\prime}{ }_{W}\right)$ and corresponding number of crosslinking events per mass unit $\left(X^{\prime}\right)$.

\begin{tabular}{|c|c|c|c|c|c|c|c|c|c|c|c|}
\hline Sample & Dose (kGy) & $M_{W}\left(\mathrm{~kg}-\mathrm{mol}^{-1}\right)$ & $X \times 10^{3}\left(\mathrm{~mol} \mathrm{~kg}^{-1}\right)$ & $G(X)$ & $\eta($ Pa s) & $M_{W}^{\prime}\left(\mathrm{kg} \mathrm{mol}^{-1}\right)$ & $X^{\prime} \times 10^{3}\left(\mathrm{~mol} \mathrm{~kg}^{-1}\right)$ & $M^{\prime}{ }_{W} / M_{W}$ & $\eta / \eta_{0}$ & $\operatorname{Ln}\left(\eta / \eta_{0}\right)$ & $\eta_{0}$ calc \\
\hline \multirow[t]{4}{*}{ A } & 0 & 38.3 & 0 & - & 349 & 42.5 & 0 & 1.11 & 1.0 & 0 & 348 \\
\hline & 6.67 & 52.8 & 3.6 & 5.4 & 1760 & 68.4 & 4.5 & 1.30 & 5.04 & 1.617 & 2429 \\
\hline & 13.3 & 64.5 & 5.3 & 4.0 & 4440 & 89.8 & 6.2 & 1.39 & 12.7 & 2.543 & 6083 \\
\hline & 33.3 & 127 & 9.1 & 2.7 & 45,360 & 33.3 & 9.0 & 1.40 & 130 & 4.867 & 47,350 \\
\hline \multirow[t]{4}{*}{ B } & 0 & 46.4 & 0 & - & 784 & 53.9 & 0 & 1.16 & 1.0 & 0 & 668 \\
\hline & 6.67 & 51.9 & 1.1 & 1.6 & 1984 & 63.7 & 1.4 & 1.23 & 1.77 & 0.508 & 1210 \\
\hline & 13.3 & 59.5 & 2.4 & 1.8 & 2600 & 76.7 & 2.8 & 1.29 & 3.32 & 1.199 & 2441 \\
\hline & 33.3 & 107 & 6.1 & 1.8 & 28,060 & 154 & 6.0 & 1.44 & 35.8 & 3.578 & 18,002 \\
\hline \multirow[t]{4}{*}{ C } & 0 & 62.9 & 0 & - & 1815 & 69.0 & 0 & 1.10 & 1.0 & 0 & 1878 \\
\hline & 6.67 & 75.6 & 1.3 & 2.0 & 4455 & 89.9 & 1.7 & 1.19 & 2.45 & 0.896 & 3872 \\
\hline & 13.3 & 85.2 & 2.1 & 1.6 & 8062 & 107 & 2.6 & 1.26 & 4.44 & 1.491 & 5774 \\
\hline & 33.3 & 445 & 6.8 & 2.1 & 54,350 & 188 & 4.6 & 0.422 & 29.9 & 3.399 & 75,069 \\
\hline
\end{tabular}

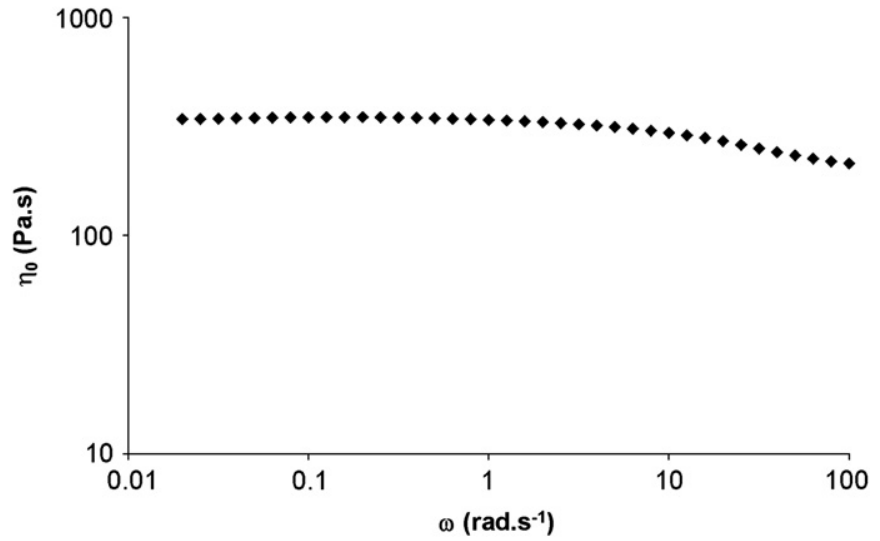

Fig. 3. Real part of the complex viscosity $(\eta)$ against angular frequency $(\omega)$ for non-irradiated sample A.

Table 3

Ratio $\eta_{0} / M_{W 0}^{3.4}$ for non-irradiated samples.

\begin{tabular}{llll}
\hline Sample & $\mathrm{A}$ & $\mathrm{B}$ & $\mathrm{C}$ \\
\hline$K \times 10^{3}\left(\mathrm{~Pa} \mathrm{~s}\left(\mathrm{~mol} \mathrm{~kg}^{-1}\right)^{3.4}\right)$ & 1.445 & 1.691 & 1.391 \\
\hline
\end{tabular}

although significantly lower. Since $M_{W}$ is expected to diverge at the gel point, the exponential function is, no doubt, an approximation, but it seems to work correctly in the whole dose range under investigation.

\subsection{Crystallinity}

DSC and SAXS data are summarized in Table 4. Lamella thickness values $\ell_{C}$ have been calculated from melting point values using the Gibbs-Thomson relationship:

$\ell_{C}=\frac{2 T_{m 0} W}{\rho_{C} \Delta H_{m 0}} \frac{1}{T_{m 0}-T_{m}}$

where $T_{m}$ and $T_{m 0}$ are, respectively, the experimental and equilibrium values of melting point, $W$ the surface energy, $\rho_{C}$ the density and $\Delta H_{m 0}$ the enthalpy of fusion of the crystalline phase. The following values have been chosen for these quantities: $T_{m 0}=415 \mathrm{~K}, W=7 \times 10^{-2} \mathrm{~J} \mathrm{~m}^{-2}, \rho_{C}=1000 \mathrm{~kg} \mathrm{~m}^{-3}$ and $\Delta H_{m 0}=$ $292 \mathrm{~kJ} \mathrm{~mol}^{-1}$ (Van Krevelen, 1990).

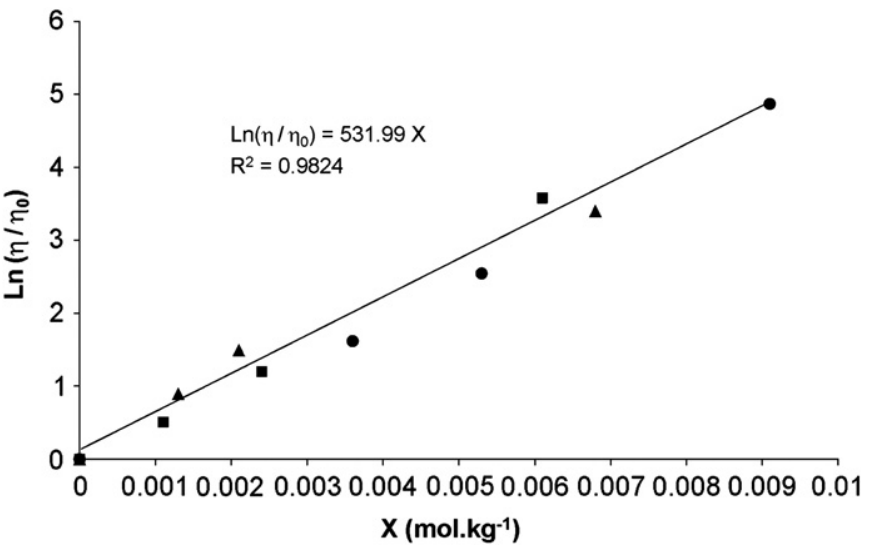

Fig. 4. $\operatorname{Ln}\left(\eta / \eta_{0}\right)$ against crosslink density $(X)$ for all samples under study: (A) (B) $\square$ and (C) $\Delta$

Table 4

DSC and SAXS results for non-irradiated samples: crystallinity ratio $\left(\chi_{C}\right)$, melting point $\left(T_{m}\right)$, lamella thickness $\left(\ell_{C}\right)$, long period spacing $\left(\ell_{P}\right)$ and interlamellar thickness $\left(\ell_{a}\right)$.

\begin{tabular}{llllll}
\hline Sample & $\chi_{C}(\%)$ & $T_{m}\left({ }^{\circ} \mathrm{C}\right)$ & $\ell_{C}(\mathrm{~nm})$ & $\ell_{P}(\mathrm{~nm})$ & $\ell_{a}(\mathrm{~nm})$ \\
\hline A & 69.3 & 128.1 & 14.3 & 20.4 & 6.1 \\
B & 70.5 & 128.9 & 15.2 & 21.8 & 6.6 \\
C & 74.0 & 130 & 16.6 & 22.1 & 5.6 \\
\hline
\end{tabular}

DSC heating rates are probably too high to give melting point values exploitable for $\ell_{C}$ determination through the GibbsThomson equation. The $\ell_{C}$ values reported here are probably underestimated and must be considered with caution. However, the main result, i.e. the relative invariance of $T_{m}$ and thus $\ell_{C}$ upon irradiation, remains valid.

Initial values reveal that $A$ and $B$ have close characteristics whereas $C$ has a crystallinity ratio and a lamella thickness significantly higher, whereas its long period is practically the same within experimental incertitudes.

As expected for low doses, irradiation does not modify significantly the polymer morphology. Indeed, the melting point and crystallinity ratio remains constant within incertitudes (Table 5). Moreover, the SAXS diffractograms, obtained for all samples $(A, B$ and $C$ ) before and after irradiation, superimpose exactly on each other. 
Table 5

DSC results for all samples before and after irradiation: crystallinity ratio $\left(\chi_{C}\right)$, melting point $\left(T_{m}\right)$ and lamella thickness $\left(\ell_{C}\right)$.

\begin{tabular}{lclll}
\hline Sample & Dose $(\mathrm{kGy})$ & $\chi_{C}(\%)$ & $T_{m}\left({ }^{\circ} \mathrm{C}\right)$ & $\ell_{C}(\mathrm{~nm})$ \\
\hline A & 0 & 69.3 & 128.1 & 14.3 \\
& 6.67 & 68.9 & 128.4 & 14.6 \\
& 13.3 & 66.6 & 128.1 & 14.3 \\
& 33.3 & 67.8 & 128.5 & 14.7 \\
$\mathrm{~B}$ & 0 & 70.5 & 128.9 & 15.2 \\
& 6.67 & 70.8 & 129.3 & 15.7 \\
& 13.3 & 71.6 & 129.2 & 15.5 \\
& 33.3 & 71.8 & 128.9 & 15.2 \\
$\mathrm{C}$ & 0 & 74.0 & 130 & 16.6 \\
& 6.67 & 72.5 & 129.6 & 16.1 \\
& 13.3 & 74.4 & 129.9 & 16.4 \\
& 33.3 & 70.4 & 129.3 & 15.7 \\
\hline
\end{tabular}

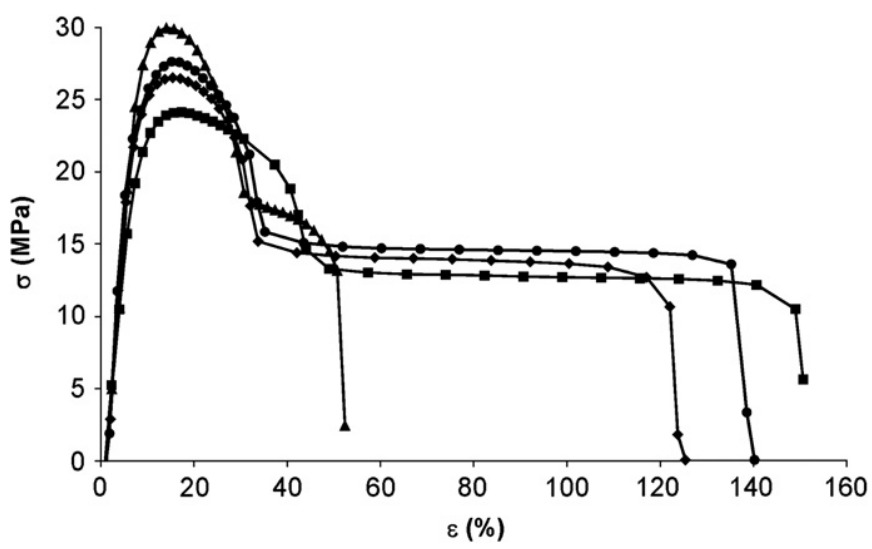

Fig. 5. Example of tensile curves for sample A before and after irradiation: $0(\boldsymbol{\square})$ $6.67(\bullet), 33.3(\bullet)$ and $133 \mathrm{kGy}(\boldsymbol{\Delta})$

Table 6

Mechanical tensile results for all samples before and after irradiation: upper yield stress $\left(\sigma_{Y}\right)$, lower yield stress $\left(\sigma_{L}\right)$, elongation at the onset of plastic plateau $\left(\varepsilon_{L}\right)$ and elongation at break $\left(\varepsilon_{R}\right)$.

\begin{tabular}{llllll}
\hline Sample & Dose $(\mathrm{kGy})$ & $\sigma_{Y}(\mathrm{MPa})$ & $\sigma_{L}(\mathrm{MPa})$ & $\varepsilon_{L}(\%)$ & $\varepsilon_{R}(\%)$ \\
\hline $\mathrm{A}$ & 0 & 24 & 13 & 52 & 138 \\
& 6.67 & 26 & 14.5 & 40 & 127 \\
& 13.3 & 27 & 15 & 36 & 127 \\
& 33.3 & 27.5 & 15 & 30 & 132 \\
$\mathrm{~B}$ & 0 & 25 & 13 & 40 & 98 \\
& 6.67 & 27 & 15 & 40 & 88 \\
& 13.3 & 30 & 16 & 38 & 76 \\
& 33.3 & 30 & 16 & 35 & 77 \\
$\mathrm{C}$ & 0 & 28 & 17 & 40 & 102 \\
& 6.67 & 33 & 17 & 40 & 72 \\
& 13.3 & 30 & 18 & 35 & 79 \\
& 33.3 & 30 & 18 & 38 & 86
\end{tabular}

\subsection{Mechanical properties}

A typical tensile curve is shown in Fig. 5 for sample A. It displays a well marked maximum followed by a quasi-horizontal plastic plateau. No stress hardening, as in high molar mass PE samples, was observed. This characteristic and the relatively low ultimate elongation value (less than $220 \%$ against more than $500 \%$ for high molar mass PE samples) confirm that the three samples under study were effectively - before irradiation - in the ductile/ brittle region.
Table 7

Ultimate elongation $\left(\varepsilon_{R}\right)$ after $133 \mathrm{kGy}$ irradiation.

\begin{tabular}{llll}
\hline Sample & A & B & C \\
\hline$\varepsilon_{R}(\%)$ & 58 & 58 & 44 \\
\hline
\end{tabular}

Four characteristics were recorded: the upper yield stress $\sigma_{Y}$, the lower yield stress $\sigma_{L}$, the elongation at the onset of the plastic plateau $\varepsilon_{L}$ and the elongation at break $\sigma_{R}$. Their values are listed in Table 6.

Irradiation effects display the following trends for all the samples:

(a) Yield stresses $\sigma_{Y}$ and $\sigma_{L}$ increase rapidly at the beginning of exposure and tend to stabilize beyond the dose of $13.3 \mathrm{kGy}$.

(b) The yield maximum sharpens: $\varepsilon_{L}$ decreases.

(c) The elongation at break $\varepsilon_{R}$ remains constant within experimental incertitudes for all samples, although a slight tendency to decrease can be suspected in samples B and C. What is sure is that it does not increase in any case.

To confirm the trends of variation in mechanical properties, we have pursued the irradiation in the same conditions until a considerably higher dose (133 kGy), far above the gelation dose. Ultimate elongation values are given in Table 7 . All the values seem to converge towards the initial $\varepsilon_{L}$ value, i.e. the onset of plastic plateau.

\section{Discussion}

If there was a doubt on the existence of a ductile/brittle transition in the $M_{W}$ scale, owing to the relatively small number of published data, the initial characteristics of the samples under study bring a confirmation. Their tensile curves display a plastic plateau, but considerably less extended than in PE samples of higher molar mass $\left(\varepsilon_{R} \approx 100-200 \%\right.$ against more than $500 \%$ ). Furthermore, no strain hardening was observed as in high molar mass samples. The representative point of samples A-C would thus effectively lie in the vertical part of the curve in Fig. 1. As a consequence, their ultimate elongation is expected to be very sensitive to any change in molar mass.

A key condition, in this study, is to change the molar mass distribution without changing the lamellar morphology. This is extremely difficult or even impossible to realize with samples differing only by the molar mass. As a matter of fact, $\ell_{a}$ tends to take a quasi-equilibrium value depending of $M_{W}$. Thermal treatments, as performed by Kennedy et al. (1994), can permit to control $\ell_{a}$ in a more or less restricted range, for a given $M_{W}$ value, but in this case, $\ell_{C}$ varies.

Crosslinking of the amorphous phase can be an interesting way if it is performed at ambient temperature, because it inhibits any further change in the lamellar morphology. Indeed, gamma irradiation in neutral atmosphere (to avoid chain scission due to oxidation) is the best way to crosslink the amorphous phase in controlled conditions. Irradiation can also create crystal defects, but they are built at low rate (Dole and Howard, 1957; Kusy and Turner, 1972) and are expected to be negligible at the irradiation doses under study.

Here, SEC and rheometric measurements gave a clear evidence of predominant crosslinking. The invariance of melting point and SAXS diffractrograms indicate the absence of significant changes in crystalline morphology. We were therefore in good conditions to appreciate the direct effect of amorphous phase crosslinking on PE mechanical properties. 
Before any discussion about the effect of crosslinking, it seems interesting to relativize this later. The entanglement molar mass $M_{e}$ of PE is about $1 \mathrm{~kg} \mathrm{~mol}^{-1}$. The concentration of entanglement knots, i.e. physical crosslinks, is:

$x_{e}=\frac{1}{2 M_{e}}\left(1-\frac{2 M_{e}}{M_{n}}\right)$

Thus, here, $x_{e}$ is of the order of $400 \times 10^{-3} \mathrm{~mol} \mathrm{~kg}^{-1}$ against less than $10 \times 10^{-3} \mathrm{~mol} \mathrm{~kg}^{-1}$ for chemical crosslinks. Thus, if radiation induced crosslinks play a role, this later cannot result just from an increase in elastic properties of the amorphous phase.

Despite its relative smallness, chemical crosslinking plays, no doubt, a role, first on yielding. As a matter of fact, one can observe that both the upper and lower yield stresses increase, even at low conversion of the crosslinking process. This behavior seems to be explainable in the frame of Galeski's (2005) theory on cavitation yielding. In the initial molar mass range under study $\left(M_{W} \leq 63 \mathrm{~kg} \mathrm{~mol}^{-1}\right)$, high density polyethylene presumably cavitates during yielding. According to Galeski (2005), an increase in molar mass would probably disfavor cavitation because it would increase the cohesive strength of the amorphous phase, but no experimental checking of this hypothesis was published (in 2003). The present results could be considered, in a certain way, as an experimental checking; however we believe that chemical crosslinking plays a role through branching, preventing chain pull-off, rather than through an increase in chain length. Here, chain branching would play a role similar as in molten state where it slows down the disentanglement by reptation. According to a simple cavitation criterion, Pawlack and Galeski (2005) and Galeski and Rozanski (2010) proposed the following relationship:

$\sigma_{Y}($ cavitation $)=\frac{3 S}{r}$

where $S$ is the surface tension and $r$ the cavity radius, which would be of the order of $\ell_{a} / 2$.

If, as proposed, crosslinking influences $\sigma_{Y}$ through the slackening of disentanglement, this means that the above relationship could be improved giving a dynamical (rheological) character to $\sigma_{Y}$, which is a possible way to rejoin the problem of time dependent fracture in polyethylene pipes under pressure (Lu and Brown, 1990).

Let us now consider fracture properties. The proposed approach of the problem was based on the idea that crosslinking of the amorphous phase increases the TMC, as schematized in Fig. 6.

If tie chains had a significant effect on fracture strength, then the behavior would be shifted to ductile regime upon irradiation. Here, relatively small changes in the fracture properties are observed in all the cases, but the trend is, no doubt, opposite to the expected one. Irradiation clearly disfavors cavitation as observed by the increase in yield stress, but disfavoring cavitation does not improve ductility. On the contrary, this later tends to decrease slowly.

Classically, when crosslinking induces embrittlement, it is assumed that the cause is a decrease in chain drawability. As a matter of fact, if $M_{C}$ is the molar mass between crosslinks, the maximum draw ration $\lambda_{\max }$ at which, in principle, fracture occurs, is theoretically proportional to $M_{C}^{1 / 2}$, i.e. also proportional to $x_{C}^{-1 / 2}, x_{C}$ is the chemical crosslink density. However, here, as it is seen above, physical crosslinking (entanglements) largely predominates over chemical crosslinking. This latter one is thus expected to have a negligible influence on the theoretical chain drawability. It seems better to invoke structural transformations occurring in the polymer during yielding. The result of these transformations could be for instance expressed in terms of "defects" size distribution, a "defect" is, for instance, a locus of stress concentration, a microvoid, etc. For reasons that remain to established, when crosslinking induces an increase in yield stress, it would also modify this distribution, favoring thus the presence of "defects" able to initiate cracking.

Another possible explanation could be linked to the observed increase in stress $\sigma_{L}$ at the plastic plateau (Table 6). Considering that, at this plateau, the polymer is still a homogeneous solid with defects of size $a$, one could tentatively apply the Griffith criterion for crack propagation:

$\frac{\pi \sigma^{2} a}{E G_{I C}} \geq 1$

where $\sigma$ would be $\sigma_{L}$ here, $a$ is the defect size, $E$ the Young modulus and $G_{I C}$ the critical rate of elastic energy release.

At least in a first approach, $E$ and $G_{I C}$ could be considered constant so that cracking would initiate at increasingly small defects, of size proportional to $\sigma_{L}^{-2}$. An irradiation dose of $33.3 \mathrm{kGy}$ would thus decrease the size of active defects by about $33 \%$ for sample A, $50 \%$ for sample B and $12 \%$ for sample C.

\section{Conclusions}

For polyethylene (PE), it seems well established that the structural parameter determining the fracture regime is the interlamellar spacing $\ell_{a}$. There is a critical value $\ell_{a c}$ of $\ell_{a}$ (in PE, $\left.\ell_{a c} \approx 6-7 \mathrm{~nm}[11]\right)$ such as the polymer displays a ductile behavior for $\ell_{a}>\ell_{a c}$ and a brittle behavior for $\ell_{a}<\ell_{a c}$ (in tension at ambient temperature and $10^{-3 \pm 2} \mathrm{~s}^{-1}$ strain rate).

$\ell_{a}$ is more or less sharply linked to molar mass so that a critical molar mass interval $M_{F}=70 \pm 30 \mathrm{~kg} \mathrm{~mol}^{-1}$ corresponds to the critical interlamellar spacing $\ell_{a c}$.

Here, three commercial PE samples, with $\ell_{a}$ values close to $\ell_{a c}$ and initial molar masses in the transition interval, were irradiated by $\gamma$ rays under nitrogen in order to crosslink the amorphous phase, and thus to increase the tie-macromolecules concentration (TMC) without changing the lamella dimensions. Since the

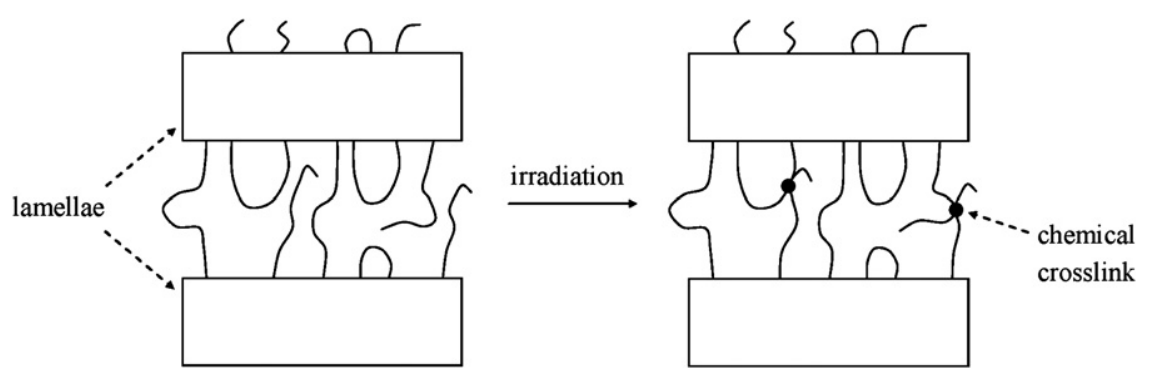

Fig. 6. Schematization of the formation of new tie macromolecules by radiation crosslinking of the amorphous phase. 
samples were initially in the transition region, they are expected to display a high sensitivity to small structural changes.

Here, crosslinking leads to an increase in yield stress, which can be understood from current theories. However, crosslinking leads to a decrease in the strain at break, which is the more surprising since an increase in TMC is generally considered as a factor favoring ductility. In a first approach, our results agree well with those of Kennedy et al. (1994), according to which molar mass does not directly control the regime of fracture ; this latter one was rather linked to interlamellar spacing. However, our results also reveal that crosslinking leads to a slow decrease in ductility without significant changes in interlamellar spacing. In other words, a structural factor disfavoring cavitation is not necessarily favorable to ductility. To explain this apparent contradiction, a precise description of the structure at the onset of necking is probably needed.

\section{References}

Chapiro, A., 1962. Radiation Chemistry of Polymeric Systems. Interscience Publishers Inc., New York.

Charlesby, A., Pinner, S.H., 1959. Proc. Roy. Soc. (Lond.) A249, 367-386.

Dole, M., Howard, W.H., 1957. J. Phys. Chem. 61, 137.

Fayolle, B., Richaud, E., Colin, X., Verdu, J., 2008. J. Mater. Sci. 43, 6999-7012.

Fayolle, B., Verdu, J., Piccoz, D., Dahoun, A., Hiver, J.M., G'sell, C., 2009. J. Appl. Polym. Sci. 111 (1), 469-475.

Fetters, L.J., Lohse, D.J., Colby, R.H., 1996. In: Mark, J.E. (Ed.), Physical Properties of Polymers Handbook. AIP Press, Woodbury, New York, p. 335.
Galeski, A., 2005. In: Michler, G.H., Balta-Calleja, F.J. (Eds.), Mechanical Properties of Polymers Based on Nanostructure and Morphology. Taylor \& Francis, Boca Raton, FL, pp. 159-211.

Galeski, A., Rozanski, A., 2010. Macromol. Symp. 298, 1-9.

Graessley, W.W., 1992. In: Mark, J.E. (Ed.), Physical Properties of Polymers. American Chemical Society, Washington, DC, p. 97.

Henning, S., Michler, G.H., 2005. In: Michler, G.H., Balta-Calleja, F.J. (Eds.), Mechanical Properties of Polymers Based on Nanostructure and Morphology. Taylor \& Francis, Boca Raton, FL, pp. 245-278.

Huang, Y.-L., Brown, N., 1991. J. Polym. Sci.: Part B: Polym. Phys. 29, 129-137.

Kennedy, M.A., Peacock, A.J., Mandelkern, L., 1994. Macromolecules 27, 5297-5310.

Krigbaum, W.R., Roe, R.-J., Smith, K.J., 1964. Polymer 5, 533-542.

Kusy, R.P., Turner, D.T., 1972. J. Polym. Sci.: Part A1: Polym. Chem. 10, 1745-1762.

Lu, X., Brown, N., 1990. J. Mater. Sci. 25, 29-34.

Miller, R.D., Macosko, C.W., 1976. Macromolecules 9 (2), 206-211.

Nitta, K.H., Tanaka, A., 2001. Polymer 42 (3), 1219-1226.

Parkinson, W., Bopp, C., Binder, D., White, J., 1965. J. Phys. Chem. 69, 828-833.

Pawlack, A., Galeski, A, 2005. Macromolecules 38 (23), 9688-9697.

Plummer, C.J.G., 2005. In: Michler, G.H., Balta-Calleja, F.J. (Eds.), Mechanical Properties of Polymers Based on Nanostructure and Morphology. Taylor \& Francis, Boca Raton, FL, pp. 215-244.

Saeda, Y., Yotsunagi, J., Yamagushi, K., 1971. J. Appl. Polym. Sci. 15, 277-292.

Saito, O., 1958. J. Phys. Soc. Jpn. 13 (2), 198-206.Saito, O., 1958. J. Phys. Soc. Jpn. 13 (12), 1451-1464.

Schnabel, W., 1978. In: Jellinek, H.G. (Ed.), Aspects of Degradation and Stabilization of Polymers. Elsevier, New York, p. 149.

Seguela, R., 2005. J. Polym. Sci.: Part B: Polym. Phys. 43, 1729-1748.

Trankner, T., Hedenqvist, M., Gedde, U.W., 1994. Polym. Eng. Sci. 34 (21), 1581-1588.

Van Krevelen, D.W., 1990. Properties of Polymers, 3rd ed. Elsevier, Amsterdam, p. $86,236,465,597,792$.

Wu, S., 1989. J. Polym. Sci.: Part B: Polym. Phys. 27, 723-741. 